\title{
Membangun MakerSpace untuk Perpustakaan Sekolah
}

\author{
Riya Fatmawati, S.IP.,M.Hum. ${ }^{* 1}$, Malta Nelisa, S.Sos.,M.Hum. ${ }^{2}$ Habiburrahman, \\ S.Pd.I.,M.A ${ }^{3}$ \\ ${ }^{1}$ Informasi Perpustakaan dan Kearsipan/ Bahasa dan Sastra Indonesia/UNP \\ ${ }^{2}$ Informasi Perpustakaan dan Kearsipan/ Bahasa dan Sastra Indonesia/UNP \\ ${ }^{3}$ Informasi Perpustakaan dan Kearsipan/ Bahasa dan Sastra Indonesia/UNP \\ *)Corresponding author, $\triangleq$ author@email.riyafatmawati@fbs.unp.ac.id
}

(Di isi oleh editor) Revisi 02/06/2019;

Diterima 04/07/2019;

Publish 08/08/2019

Kata kunci: kata kunci a, kata kunci b, kata kunci c

\begin{abstract}
Abstrak
Program Kemitraan Masyarakat ini bertujuan untuk meningkatkan pelayanan pada perpustakaan sekolah SMPN 1 Nan Sabaris, Kecamatan Nan Sabaris, Kabupaten Padang Pariaman. Target yang ingin dicapai dalam kegiatan ini adalah, 1) mengadakan makaerspace sebagai media literasi pada siswa sekolah SMPN 1 Nan Sabaris, 2) siswa mempunyai fasilitas untuk bisa mengembangkan ide dan kreatifitas yang dimiliki, 3) pengelola perpustakaan lebih cakap dan memiliki keterampilan yang bisa dimanfaatkan dan bisa di share kepada siswa yang berkunjung pada perpustakaan sekolah SMPN 1 Nan Sabaris Kecamatan Nan Sabaris Kabupaten Padang Pariaman. Metode yang digunakan dalam pelaksanaan ini adalah 1) memberikan satu perangkat computer kepada pengelola perpustakaan sekolah SMPN 1 Nan Sabaris, 2) menginstalkan softwaresoftware yang bisa mengembangkan kreatifitas siswa, 3) melatih pengelola perpustakaan dan siswa dalam menggunakan media makerspace. Pelaksanaan kegiatan akan dilakukan selama delapan bulan yang diawali dengan persiapan yang mencakup pemantapan jadwal dan koordinasi dengan pihak sekolah SMPN 1 Nan Sabaris. 1) memberikan sebuah computer berupa laptop untuk perpustakaan sekolah SMPN 1 Nan Sabaris, 2) Menginstalkann software photoshop, software coreldrow dan software google sketcup dan 3) melakukan softskill learning untuk pengelola perpustakaan sekolah beserta siswa sekolah SMPN 1 Nan Sabaris Kecamatan Nan Sabaris Kabupaten Padang Pariaman.
\end{abstract}


This is an open access article distributed under the Creative Commons Attribution License, which permits unrestricted use, distribution, and reproduction in any medium, provided the original work is properly cited. 02019 by author (s)

\section{PENDAHULUAN}

\section{Analisis Situasi}

Makerspace adalah sebuah ruang yang dirancang khusus bagi para individu pembuat produk. Makerspace merupakan istilah yang sudah familiar di negara Amerika dan Inggris yang menyediakan tempat khusus dan didesain secara khusus bagi orang-orang untuk mengeluarkan ide dan berkreasi. Menurut Chan dan Poddick, (2014) mengatakan makerspace merupakan konsep dan latar belakang ruang kegiatan pada sebuah perpustakaan yang menyediakan alat-alat atau perangkat-perangkat yang bisa digunakan, kegiatan pada ruang makerspace adalah selain mencoba mengotak-atik barang yang sudah ada bisa juga membuat kreasi baru yang mungkin belum pernah ada sebelumnya. Makerspace sangat membantu siswa dalam menuangkan ide-ide yang mereka miliki, dan bisa mengasah dan mengembangkan keterampilan yang ada sehingga siswa dibekali dengan keterampilan yang bermanfaat.

Berdasarkan penelitian Mann, L. (2018) yang dilakukan di Texas pada tahun 2018 mengatakan 65\% pada saat ini anak usia sekolah akan lebih mapan dalam bekerja dan berkarir jika mereka tidak hanya fokus pada penelusuran informasi akan tatapi memiliki karya dan mempunyai keterampilan. Oleh sebab itu, ada baiknya di perpustakaan sekolah disediakan layanan makerspace yang bisa menambah keterampilan siswa karena ruang makerspace tidak hanya untuk sekedar ruang mendapatkan informasi saja akan tetapi mereka bisa mengolah informasi tersebut menjadi sebuah kreatifitas yang bisa menambah keterampilan, tidak hanya itu pengelola perpustakaan sekolah dituntut lebih bisa mengembangkan diri dan memiliki keteampilan khusus yang bisa dibagi untuk siswa yang datang keperpustakaan, pengelola perpustakaan dituntut untuk memenuhi layanan perpustakaan yang sesuai dengan trend dan perkembangan zaman. Adapun salah satu model layanan perpustakaan terbaru saat ini adalah perpustakaan mempunyai sebuah ruang untuk makerspace.

Menurut Yusuf (2007:2) perpustakaan sekolah adalah perpustakaan yang ada dilingkungan sekolah yang bertujuan untuk memenuhi kebutuhan informasi bagi masyarkat dilingkungan sekolah yang bersangkutan. Hal senada juga tertera dalam Standar Perpustakaan Sekolah (SNI 7329-2009), perpustakaan sekolah bertujuan menyediakan pusat sumber belajar sehingga dapat membantu pengembangan dan peningkatan minat baca, literasi informasi, bakat, dan kemampuan peserta didik. Perpustakaan sekolah bertujuan Untuk menyediakan sumber informasi dan tempat belajar sehingga dapat membantu mengembangkan dan meningkatkan minat baca dan mengembangkan pengetahuan yang sudah ada.

Berdasarkan observasi awal pada perpustakaan SMPN 1 Nan Sabaris Kabupaten Padang pariaman ditemukan permasalahan sebagai berikut, pertama kurang maksimalnya layanan yang diberikan oleh pengelola perpustakaan sekolah kepada siswa, hal ini terlihat dari jenis layanan yang ada pada perpustakaan sekolah yang menyediakan layanan baca ditempat dan layanan peminjaman. Untuk layanan baca siswa hanya bisa menggunakan waktu istrihat saja sehingga ini sangat menghambat siswa untuk melakukan aktifitas membaca di sekolah. Sedangkan untuk layanan peminjaman hanya boleh dilakukan oleh wali kelas siswa dan hal ini sangat tidak memungkinkan siswa dapat berkembang dan memiliki keterampilan. 


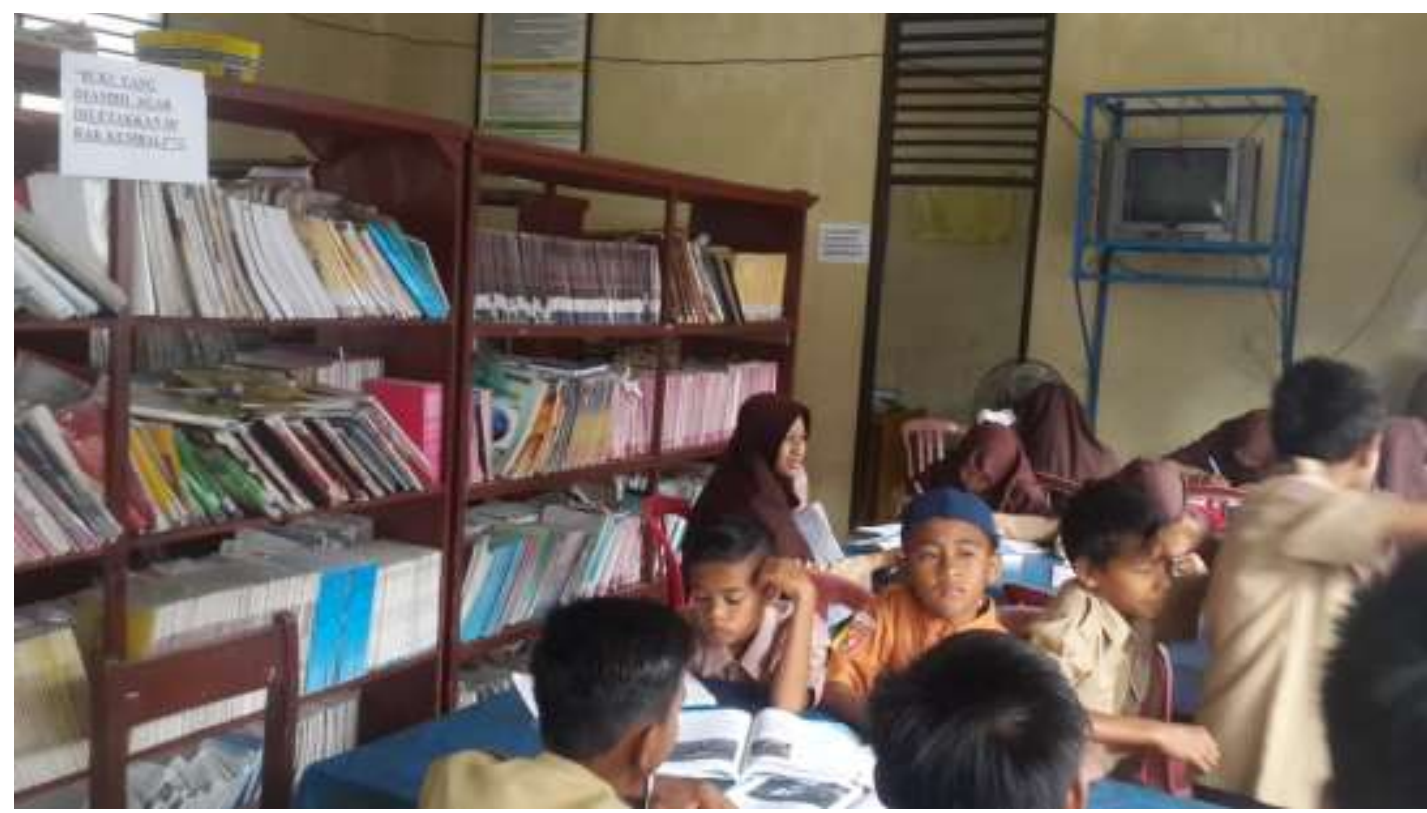

Gambar 1. Ruang Baca Perpustakaan Sekolah SMPN 1 Nan Sabaris

Pada gambar diatas dapat dilihat siswa sedang memanfaatkan ruang baca perpustakaan sekolah disaat jam istirahat. Mereka melakukan peminjaman buku dengan system layanan baca ditempat.

Permasalahan kedua adalah kurangnya jumlah kunjungan siswa ke perpustakaan sekolah hal ini terlihat dari buku kunjungan yang diisi oleh siswa yang datang keperpustakaan. Jumlah peminat yang datang setiap hari ke perpustakaan tidak lebih dari 20 pengunjung setiap minggunya yang datang keperpustakaan sekolah dari 627 jumlah keseluruhan siswa. Dari hasil wawancara dengan beberapa siswa kelas sembilan mengatakan mereka malas datang keperpustakaan karena dalam perpustakaan tidak ada yang bisa dilakukan selain membaca. Sehingga kegiatan yang ada disekolah dirasakan sangat monoton dan tidak bervariasi. Hal ini tentu bisa kita rasakan dari aktivitas siswa yang dimulai dari jam tujuh pagi hingga sore hari mereka tidak lepas dari belajar dan membaca.

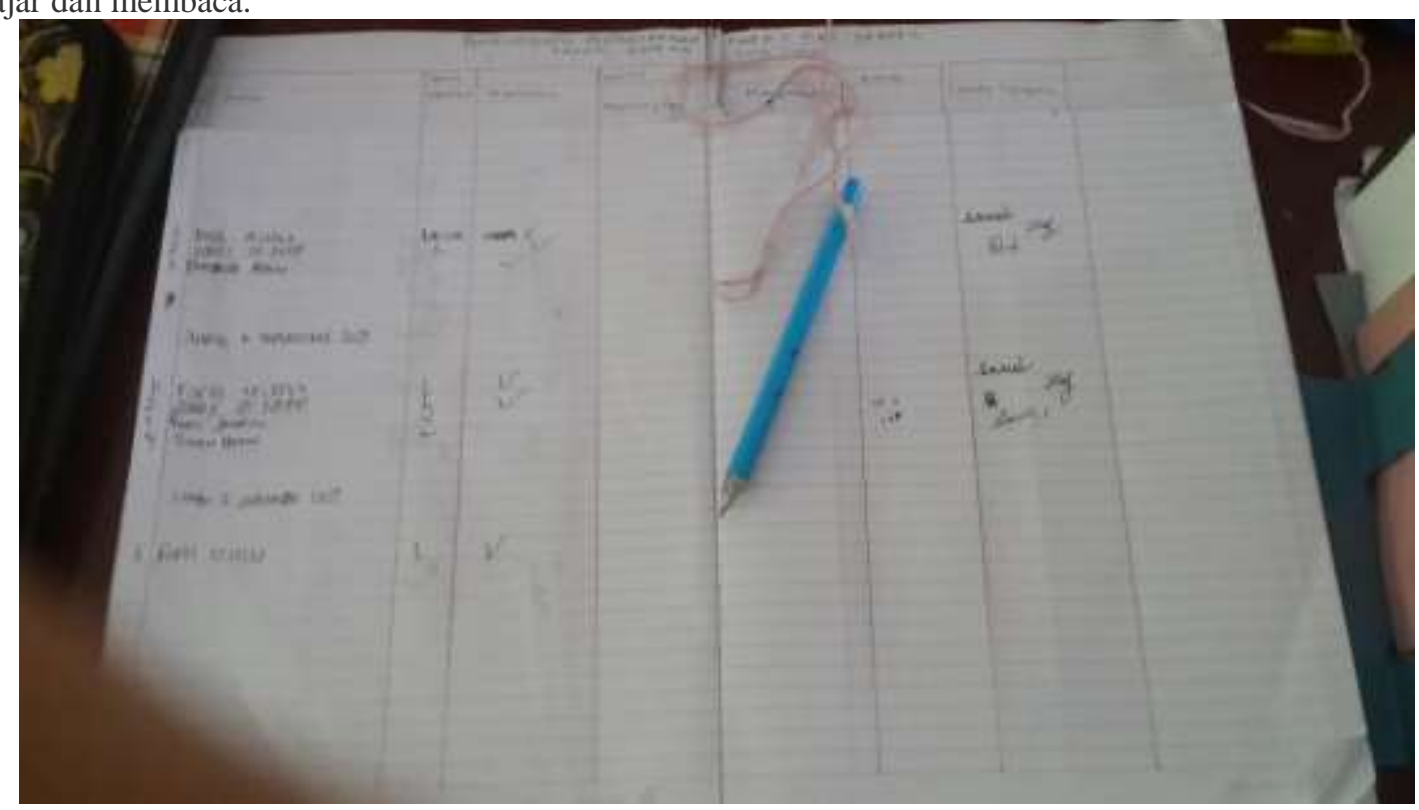

Gambar 2. Buku Kunjungan Perpustaaan Sekolah SMPN 1 Nan Sabaris

Pada gambar 2 diatas dapat dilihat jumlah pengguna perpustakaan yang berkunjung keperpustakaan dalam sehari, tidak lebih dari 20 orang pengunjung yang masuk keperpustakaan, padahal siswa disekolah SMPN 1 Nan Sabaris mencapai ratusan siswa. 
Permasalahan ketiga buku-buku yang disediakan selama ini hanyalah buku monograf yang berjumlah 8.000 eksemplar, buku-buku monograf yang ada lebih banyak buku yang berkaitan dengan pelajaran disekolah saja, seperti buku-buku matematika, bahasa Indonesia, seni budaya dan lain sebagainya. Sedangkan untuk bacaan umum perpustakaan sekolah menyediakan buku-buku cerita dongeng dan cerita rakyat. Perpustakaan sekolah tidak menyediakan buku-buku kreatif seperti cara mudah mengedit foto, cara mudah merancang baju dan lain sebagainya. Hal ini menyebabkan siswa malas datang berkunjung keperpustakaan karena buku-buku yang berkaitan dengan pelajaran sudah dipinjamkan kepada wali kelas masing-masing.

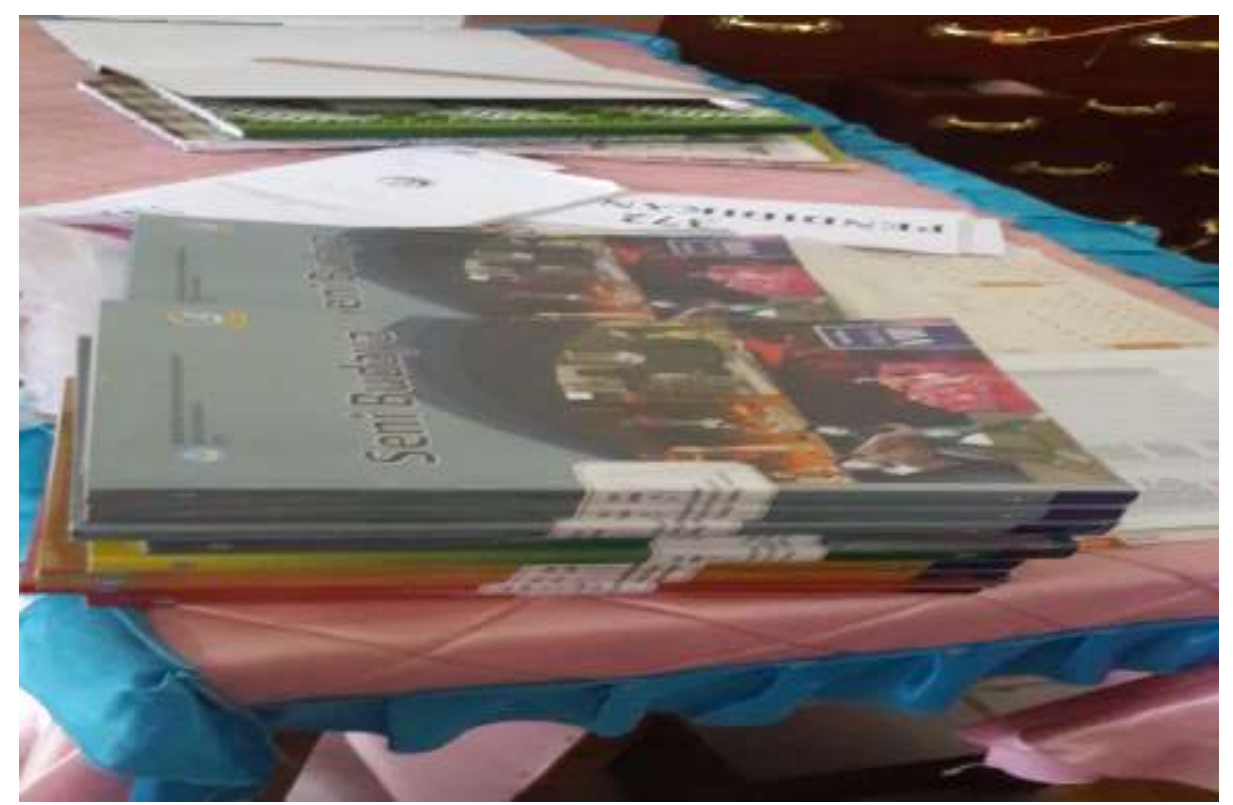

Gambar 3. Contoh Buku Koleksi Perpustakaan Sekolah SMPN 1 Nan Sabaris.

Pada gambar 3 diatas dapat dilihat salah satu contoh buku yang ada pada perpustakaan sekolah SMPN 1 Nan Sabaris. Buku-buku yang disediakan hanya buku teks, dan jarang sekali ada buku-buku pengayaan, sehingga siswa yang datang keperpustakaan hanya untuk keperluan membuat tugas saja.

Permasalahan keempat pengelola perpustakaan sekolah SMPN 1 Nan Sabaris terdiri dari dua orang pengelola inti dan tiga orang pengelola pendamping perpustakaan, dari keseluruhan pengelola perpustakaan tidak satu orang pun memiliki keterampilan yang bisa dibagi dengan siswa dan hanya beberapa yang memiliki softskill dalam literasi informasi, hal ini diperoleh data dari hasil wawancara terhadap pengelola perpustakaan.

\section{Solusi dan Target}

Kegiatan ini dilakukan pada sebuah ruangan yang sudah disediakan oleh pihak sekolah SMPN 1 Nan Sabaris, yaitu disalah satu pojok pada ruang perpustakaan sekolah yang berukuran empat kali empat meter. Waktu pelaksanaan kegiatan ini terdiri dari tiga hari dimulai tanggal 29 dan 30 agustus 2019 sampai 1 september 2019. Target yang ingin di capai dalam kegiatan ini adalah :

1. Menambah layanan pada perpustakaan sekolah SMPN 1 Nan Sabaris dengan menyediakan layanan makaerspace pada salah satu pojok baca dalam perpustakaan sekolah SMPN 1 Nan Sabaris. Target yang dicapai dalam hal ini adalah perpustakaan sekolah SMPN 1 Nan Sabaris mempunyai layanan baru yaitu layanan makerspace.

2. Memberikan seperangkat computer berupa laptop pada perpustakaan SMPN 1 Nan Sabaris. Target yang ingin dicapai adalah pihak perpustakaan sekolah mempunyai sebuah sarana untuk menyalurkan ide-ide kreatif siswa. 
3. Menginstalkan software photoshop, software coreldrow dan software google scetcup pada laptop tersebut. Target yang ingin dicapai dalam hal ini adalah agar pihak perpustakaan sekolah SMPN 1 Nan Sabaris mempnyai sarana dan memiliki softskill.

4. Melatih pengelola perpustakaan untuk menggunakan software photoshop, software coreldrow dan software google scetcup. Target yang ingin dicapai dalam hal ini adalah agar pengelola perpustakaan mempunyai keterampilan agar dapat di share kepada siswa .

5. Melatih beberapa siswa untuk menggunakan software photoshop, software coreldrow dan software google scetcup. Dalam hal ini target yang ingin dicapai adalah agar siswa dapat memanfaatkan software-software yang sudah disediakan.

\section{METODE PELAKSANAAN}

\section{Tempat dan Waktu}

Pelaksanaan kegiatan Pengabdian Kepada Masyarakat diadakan pada Perpustakaan Sekolah SMPN 1 Nan Sabaris Kabupaten Padang pariaman. Waktu pelaksanaan dilakukan selama tiga hari dimulai dari tanggal 29-30 Agustus 2019 sampai 01 September 2019.

\section{Khalayak Sasaran}

Khalayak sasaran dalam pengabdian ini adalah pengelola perpustakaan sekolah SMPN 1 Nan Sabaris dan pengguna perputakaan, disini adalah siswa sekolah SMPN 1 Nan Sabaris.

\section{Metode Pengabdian}

Berdasarkan berbagai permasalahan mitra yang telah diuraikan sebelumnya, maka metode yang ditawarkan untuk menyelesaikan persoalan pada layanan perpustakaan sekolah SMPN 1 Nan Sabaris adalah melalui beberapa tahapan sebagai berikut:

1. Membuat layanan MakerSpace untuk siswa di Perpustakaan Sekolah SMPN 1 Nan Sabaris, Kecamatan Nan Sabaris, Kabupaten Padang Pariaman dengan melakukan penambahan seperangkat komputer berupa laptop

2. Melakukan pengisian software photoshop, software coreldrow dan software google scetcup. yang bisa digunakan secara offline.

3. Membuat panduan penggunaan software photoshop, software coreldrow dan software google scetcup.

4. Melakukan softskill learning kepada pengelola perpustakaan sekolah SMPN 1 Nan Sabaris dalam menggunakan software photoshop, software coreldrow dan software google scetcup.

5. Memberi pelatihan kepada siswa sekolah yang merupakan perwakilan dari kelas 8 dan kelas 9 dalam menggunakan software photoshop, software coreldrow dan software google scetcup.

\section{Indikator Keberhasilan}

1. Membersihkan ruangan untuk digunakan sebagai salah satu layanan makerspace.

2. Menginstalkan software photoshop, software coreldrow dan software google scetcup pada laptop yang sudah disediakan.

3. Memberi panduan kepada pengelola perpustakaan dalam menggunakan software photoshop, software coreldrow dan software google scetcup.

4. Melakukan softskill learning kepada pengelola perpustakaan sekolah SMPN 1 Sabaris dalam menggunakan software photoshop, software coreldrow dan software google scetcup.

5. Memberikan pelatihan kepada beberapa perwakilan siswa kelas delapan dan siswa kelas Sembilan dalam menggunakan software photoshop, software coreldrow dan software google scetcup.

\section{Metode Evaluasi}

Ada beberapa tahap evaluasi yang dilakukan diantaranya,

1. Evaluasi awal digunakan untuk melihat system layanan yang ada pada perpustakaan sekolah SMP N 1 Nan Sabaris. 
2. Evaluasi proses digunakan untuk mengukur kemampuan pengelola perpustakaan dalam penggunaan software photoshop, software coreldrow dan software google scetcup.

3. Evaluasi akhir digunakan untuk mengukur keterpakaian layanan makerspace untuk siswa dalam mengembangkan ide dan kreatifitas mereka.

Peran mitra dalam pelaksanaan program ini ialah menyediakan ruang pada perpustakaan sekolah SMPN 1 Nan Sabaris yang bisa dipergunakan untuk layanan makerspace dan menyediakan tenaga pengelola perpustakaan yang akan dituntun untuk menggunakan ruang makerspace serta menyediakan beberapa orang siswa yang akan dilatih untuk menggunakan ruang makerspace.

\section{HASIL DAN PEMBAHASAN}

A. Menambah Layanan Perpustakaan Sekolah

Layanan perpustakaan biasanya terdiri sari layanan sirkulasi yang digunakan untuk layanan peminjaman dan pengembalian dan layanan referensi yang digunakan untuk layanan baca ditempat. Pada perpustakaan sekolah biasanya hanya ada satu layanan yaitu layanan sirkulasi saja, dan itu pun buku-buku yang disediakan sangat terbatas, jarang sekali sekolah-sekolah memiliki koleksi pengayaan seperti koleksi novel dan sejenisnya. Oleh sebab itu, tim pengabdi melakukan perombakan layanan yang sudah ada pada perpustakaan sekolah SMPN 1 Nan Sabaris untuk menambah sebuah ruangan yang disebut dengan layanan makerspace. Pada layanan ini, siswa disekolah datang keperpustakaan tidak hanya membaca buku ketika ada tugas sekolah dari guru, akan tetapi mereka datang ke perpustakaan bisa mengembangkan kemampuan dan skill yang mereka miliki. Pada layanan makerspace ini disediakan :

1. Sebuah ruangan untuk digunakan sebagai layanan makespace. Dalam hal ini pihak sekolah dan pihak perpustakaan yang berperan untuk menyediakan ruangan.

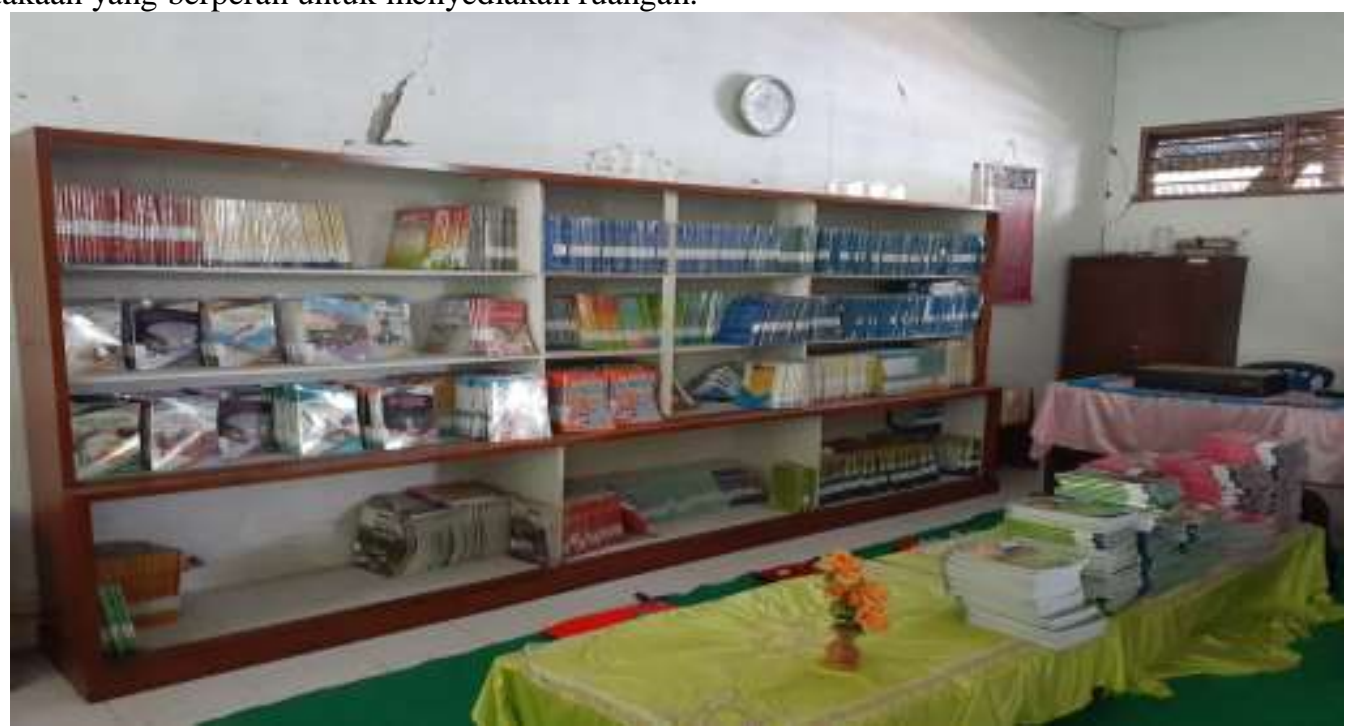

Gambar 7. Ruangan yang akan digunakan untuk layanan makerspace

Pada gambar 7 diatas merupakan ruangan yang akan disediakan oleh pihak sekolah SMPN 1 Nan Sabaris sebagai ruang Makerspace untuk siswa di perpustakaan sekolah SMPN 1 Nan Sabaris.

2. Menyediakan seperangkat Komputer berupa laptop yang berukuran 15 inci. Dalam hal ini tim memilih perangkat yang berukuran kapasitas isi yang besar karna akan digunakan untuk penginstalan software kreatifitas yang akan diguanakan oleh siswa untuk mengembangkan ide dan kreatifitas mereka. 


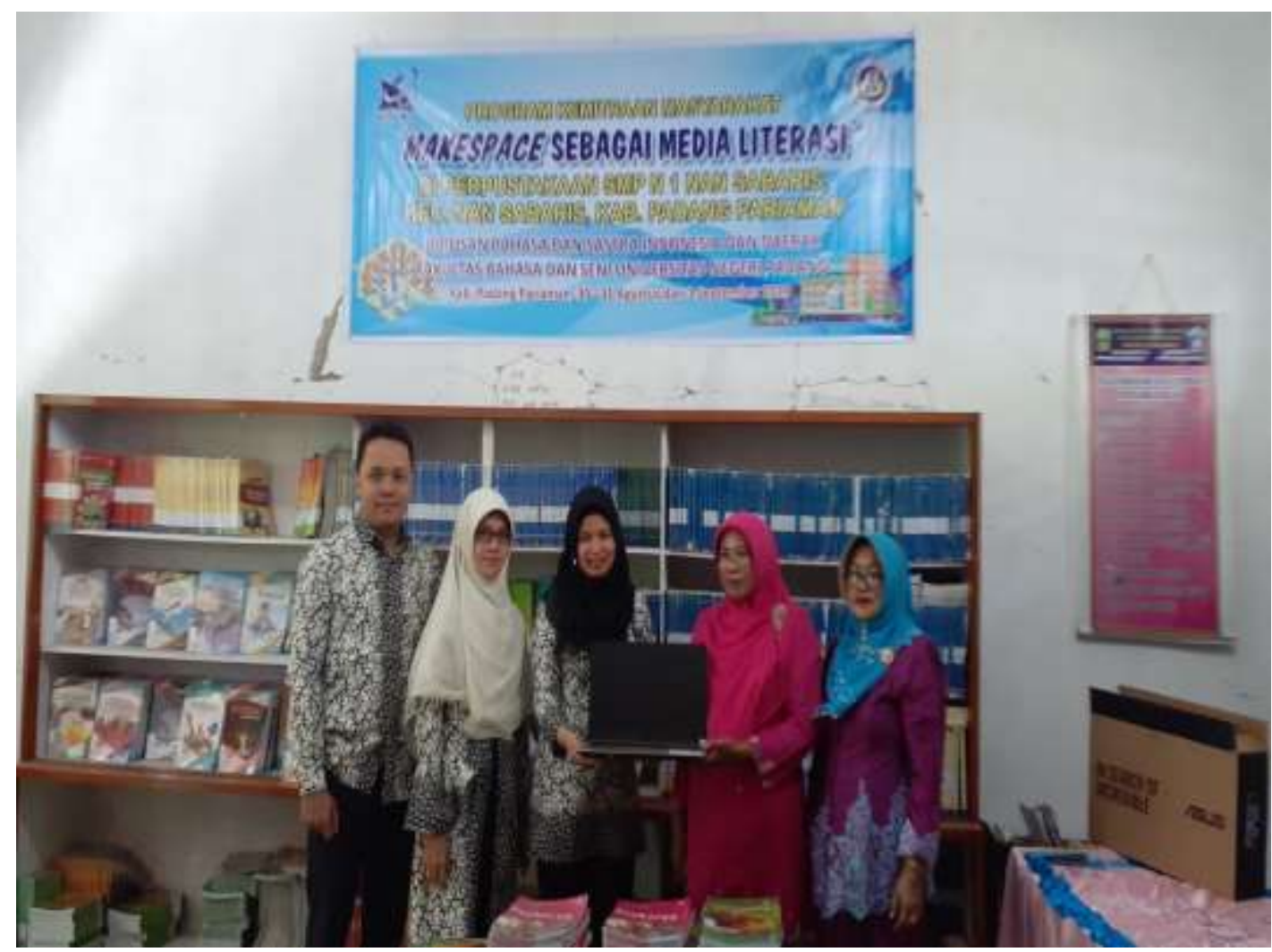

Gambar 8. Serahterima laptop kepada kepala sekolah dan pengelola perpustakaan SMPN 1 Nan Sabaris.

Gambar 8 merupakan gambar yang menjelaskan serah terima peralatan yang diberikan kepada pihak perpustakaan sekolah SMPN 1 Nan Sabaris sebagai salah satu sarana pada ruang makerspace, yaitu laptop yang berisi software-software kreatif yang akan diinstalkan.

3. Menginstalkan software photoshop, software coreldrow dan software google scetcup. Pada laptop yang sudah disediakan. software photoshop, software coreldrow dan software google scetcup ini bisa digunakan oleh siswa disaat offline. Jadi tidak perlu menggunakan jaringan internet sehingga memudahkan siswa dalam penggunaannya. 




Gambar 9. Proses Penginstalan software photoshop, software coreldrow dan software google scetcup.

Pada gambar diatas terlihat tim pengabdi sedang meninstalkan beberapa software yang bisa digunakan untuk layanan makerspace. Software-software ini bisa diguanakan saat offline sehingga bisa mengoptimalkan layanan makerspace yang sudah disediakan.

\section{B. Melakukan softskill learning}

Kegiatan ini merupakan media dalam penyampaian materi yang gunakan untuk mengoptimalkan ruang makerspace. Beberapa hal yang disampaikan dalam softskill learning adalah cara menggunakan software photoshop, software coreldrow dan software google scetcup. Peserta yang mengikuti softskill learning adalah pengelola perpustakaan sekolah SMPN 1 Nan Sabaris, dan beberapa orang siswa sekolah yang merupakan perwakilan dari kelas delapan dan kelas Sembilan. Dalam hal ini peserta dibimbing secara individual untuk mengikuti langkah-langkah penggunaan software photoshop, software coreldrow dan software google scetcup. 


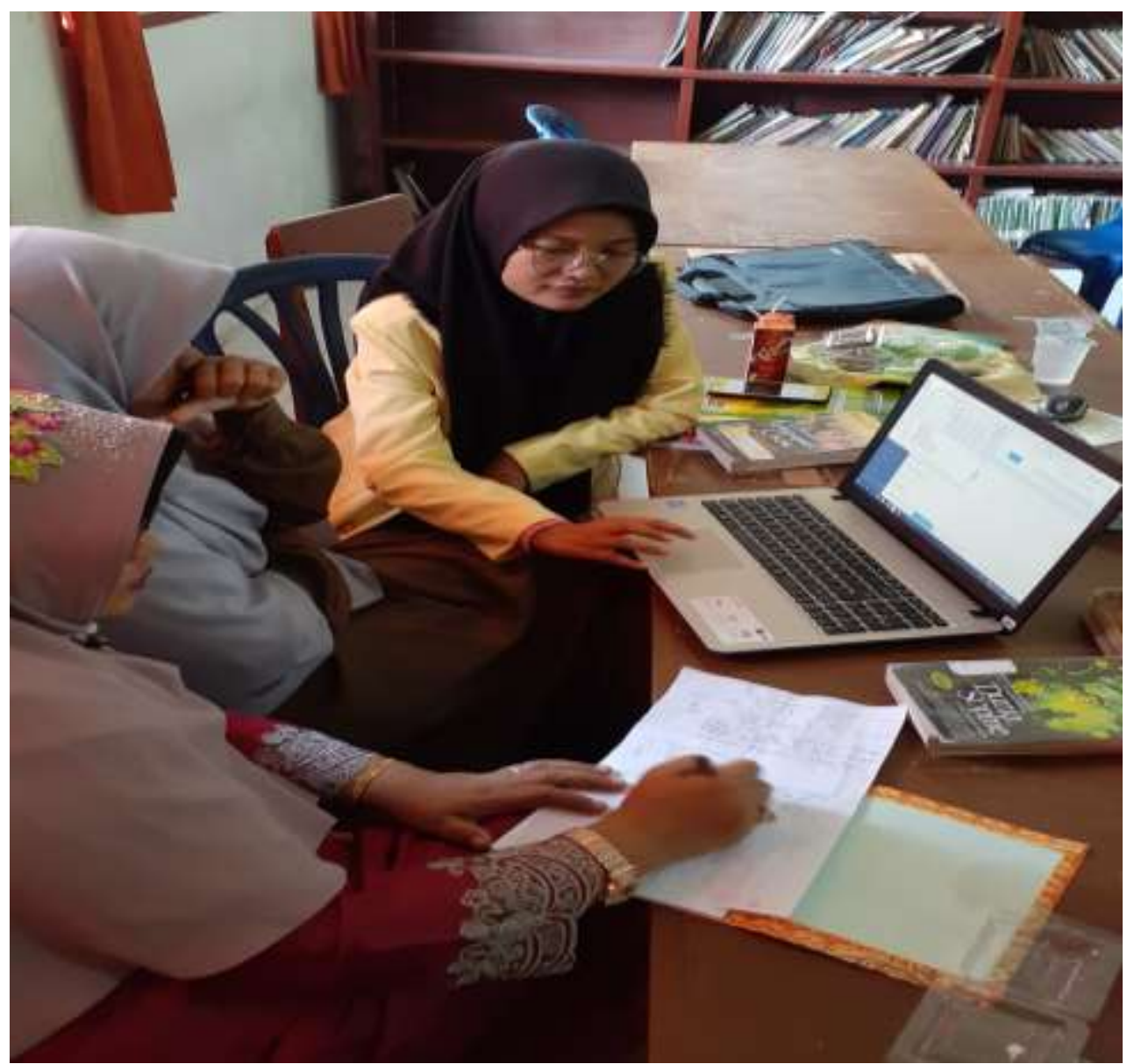

Gambar 10. Proses Bimbingan secara individual kepada Pengelola Perpustakaan Sekolah.

Pada gambar diatas terlihat tim pengabdi sedang melakukan bimbingan secara individual kepada pengelola perpustakaan sekolah SMPN 1 Nan Sabaris. Para pustakawan terlihat antusias dalam mengikuti bimbingan. 


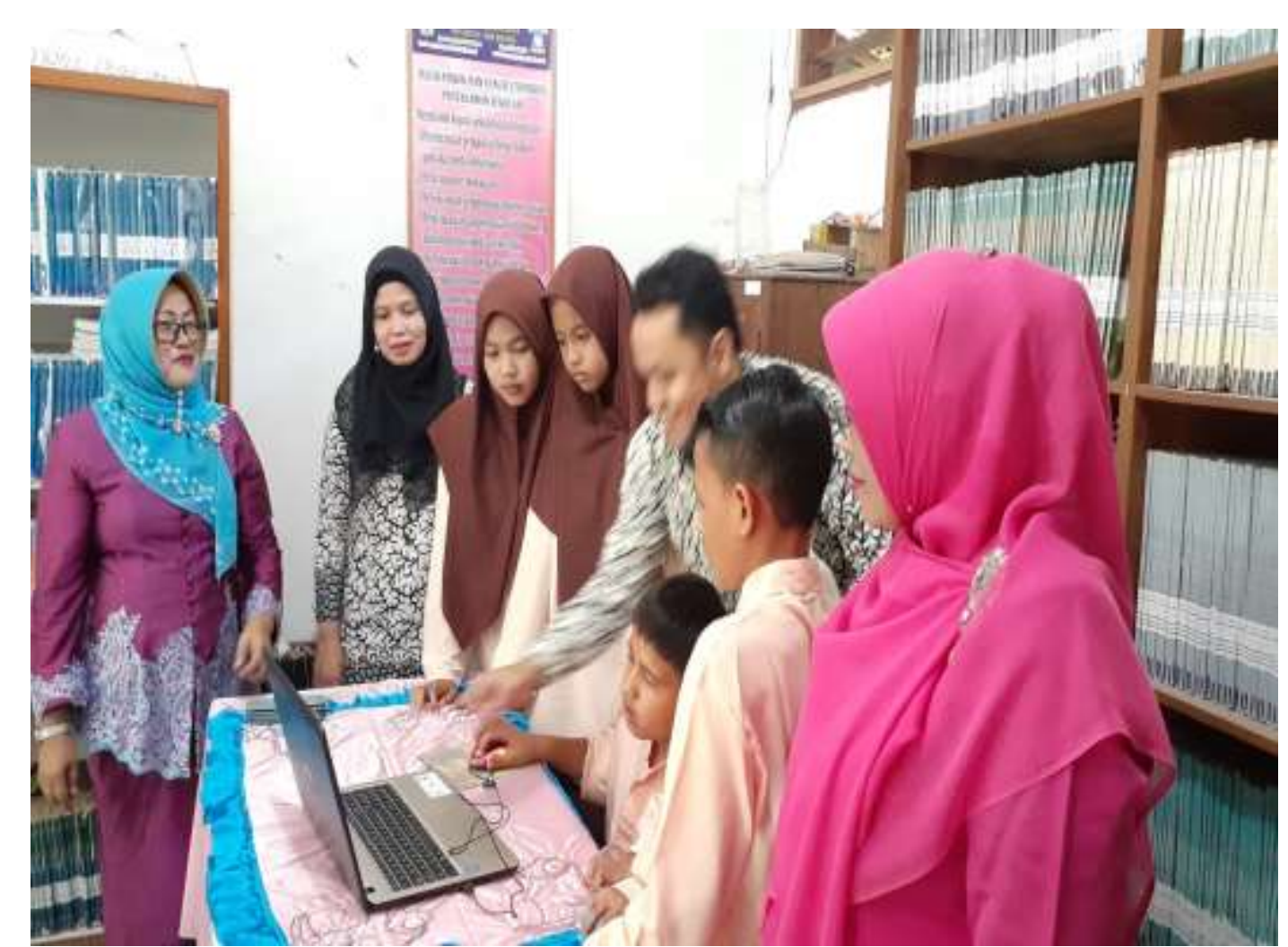

Gambar 11. Bimbingan penggunaan software pada perwakilan siswa kelas 8 dan kelas 9 SMPN 1 Nan Sabaris.

Pada gambar diatas terlihat bahwa tim pengabdi sedang melakukan pelatihan pengunaan software photoshop, software coreldrow dan software google scetcup kepada beberapa orang siswa yang merupakan perwakilan dari kelas delapan dan kelas Sembilan.

\section{KESIMPULAN}

Pada sebuah perpustakaan, layanan merupakan ujung tombak untuk meraih pengungjung sebanyakbanyaknya. Ada dua jenis layanan yang biasa digunakan pada sebuah perpustakaan yaitu layanan sirkulasi dan layanan referensi, layanan sirkulasi dipergunakan untuk peminjaman dan pengembalian buku, sedangkan layanan referensi merupakan layanan Tanya tawab, atau layanan yang fasilitas buku-bukunya hanya boleh baca ditempat. Seiring perkembangan jaman, perpustakaan saat ini lebih dituntut untuk terus berkembang sehingga peminat perpustakaan tetap bisa dipertahankan, untuk meningkatkan peminat atau pengunjung perpustakaan tersebut adalah dengan menambah system layanan yang ada pada perpustakaan. Makerspace merupakan metode jenis layanan terbaru, dimana perpustakaan menyediakan sebuah ruang untuk pengunjung dan bisa menghasilkan ide-ide kreatif yang bisa dikembangkan.

Berdasarkan hal diatas, diharapkan setiap perpustakaan lebih bisa mengembangkan diri dan mengikuti trend terbaru pada perpustakaan. 


\section{DAFTAR PUSTAKA}

Chan, D.L. and Spodick, E. 2014. Space development. New Library World, Vol. 115 Nos 5/6, pp. 250-262, available at: http://dx.doi.org/10.1108/NLW-04-2014-0042 (accessed 3 September2015).

Mann, L. 2018. Making a Place for Makerspaces in Information Literacy. Reference \& User Services Quarterly, 58(2), 82-86. Retrieved from http://search .ebscohost.com/login.aspx?direct $=$ true $\& d b=l x h \& A N=134186679 \&$ site $=$ ehost-live

Massis, B.E. 2014. What's new in libraries. New Library World, Vol. 115 Nos 5/6, pp. 285 - 288, available at: http://e-resources.perpusnas.go.id:2141/10.1108/NLW-03-2014-0030 (accessed 3 September 2015 ).

Abram, S. 2013. Makerspaces in libraries, education, and beyond. Internet@ Schools, Vol. 20 No. 2, pp. 18 - 22, available at: www.questia.com/magazine/1P3-2918635431/makerspaces-inlibraries-education-and-beyond (accessed 13 May 2015 ).

Burke, J. 2015. Making sense: can makerspaces work in academic libraries?. ACRL 2015, Portland, OR, 25-28 March, pp. 497 - 504, available at: www.ala.org/acrl/sites/ala.org.acrl/files/content/conferences/confsandpreconfs/2015/Burke. pdf (accessed 14 May 2015 ). 